\title{
Deterministic ChaOs in Forests
}

\author{
BEZAK, K.
}

Abstract: A forest is a chaotic non-linear dynamic system. The rules of forest growth are complex equations of growth and development. The solutions are complex numbers, while their mapped forms are dendrograms in which vertical directions show amplitudes or multidimensional vectors. Horizontal directions show space and time. Complex numbers are sets that represent possible physical states and form an abstract complex vector space of growth and increment. Integration of complex numbers results in increment and further integration results in the growth of diameter and height structure. Complex numbers are the topological dimension of a forest, while sets of complex numbers are the fractal dimension of a forest. Complex equtions are qualitative models for quantitative, numerical predictions of forest growth and development. Nature obeys relatively few basic laws. Th laws of forest growth and development are complex equations and universal tools for modeling multidimensional forest dynamics.

Key words: deterministic chaos, complex equations, complex numbers, dendrograms
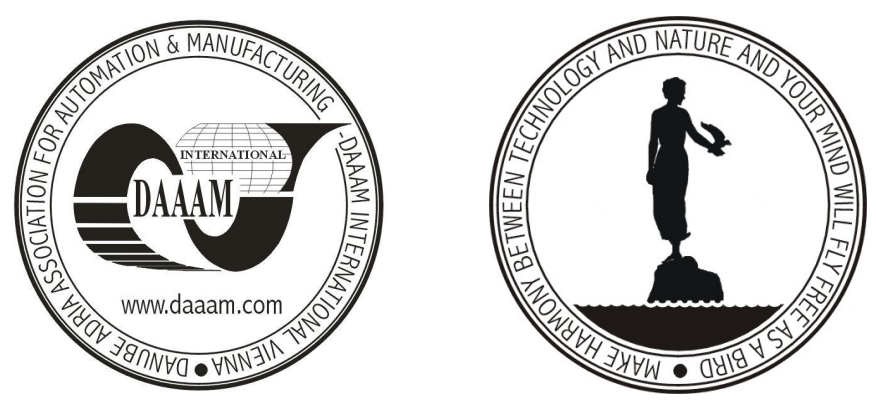

Authors' data: Dr. Sc. Bezak, K[arlo], Hrvatske šume d.o.o., 10000 Zagreb, Croatia, karlo.bezak@hrsume.hr

This Publication has to be referred as: Bezak, K. (2007). Deterministic Chaos in Forests, Chapter 42 in DAAAM International Scientific Book 2007, B. Katalinic (Ed.), Published by DAAAM International, ISBN 3-901509-60-7, ISSN 1726-9687, Vienna, Austria

DOI: $10.2507 /$ daaam.scibook.2007.42 